\title{
Enhancing informal patient education in nursing practice: A review of literature
}

\author{
Patrick J. Dunn ${ }^{* 1,2}$, Karen L. Milheim ${ }^{3}$ \\ ${ }^{1}$ Patient and Healthcare Innovation, American Heart Association, Dallas, United States \\ ${ }^{2}$ College of Health Sciences, Walden University, Minneapolis, United States \\ ${ }^{3}$ Richard W. Riley College of Education and Leadership, Walden University, Minneapolis, United States
}

Received: July 25, 2016

DOI: $10.5430 /$ jnep.v7n2p18
Accepted: September 8, $2016 \quad$ Online Published: September 18, 2016

URL: http://dx.doi.org/10.5430/jnep.v7n2p18

\begin{abstract}
Objective: Informal patient education is a common practice used by nurses in the healthcare setting. Informal methods use quick delivery instruction, and often promote self-directed learning and focus on specific tasks, based on the needs of the patient. While there are effective models for more structured patient education programs, they are not typically applicable to informal instructional situations, such as at a patient's bedside, or upon discharge. The purpose of this paper is to: a) define how informal patient education manifests itself in healthcare settings, b) identify, through a review of literature, potential issues arising from informal patient education practices, and c) suggest ways nurses can further support and enhance informal patient education to help overcome these issues.

Methods: This review of literature explores research and findings relevant to informal patient education in healthcare settings, including an examination of potential issues related to this often spontaneous, less-structured approach. Also, this review reveals findings that inform practitioners and researchers in this field with further ways to improve informal patient education practices. Results: While informal patient education holds a valuable place in healthcare settings, it also presents issues related to areas such as quality control, assessment, and curriculum. Without addressing these issues, research shows that healthcare providers, including nurses, risk a myriad of negative outcomes affecting both the patient and the organization. An analysis of the literature informed recommendations of strategies to support and enhance informal patient education, guided by four areas: desire to learn, learning by doing, feedback, and reflection. Discussion: While patient education is frequently informal, it can be supported and enhanced to help overcome challenges brought about by this type of delivery. The discussion provides specific ways nurses can help enhance informal instruction in practice.

Conclusions: Informal patient education remains prevalent in patient care, but it has drawbacks. By incorporating new strategies in practice, nurses can work towards enhancing and improving instances of informal instruction to make it more effective and productive.
\end{abstract}

Key Words: Patient education, Informal learning, Health literacy, Health education, Adult learning

\section{INTRODUCTION}

Patient education frequently occurs in an informal manner; it is often self-directed, self-managed, and focused on specific tasks in response to particular needs. ${ }^{[1]}$ Patient education sits at the intersection of healthcare and educational systems, making it necessary to continue to develop quality meth-

*Correspondence: Patrick J. Dunn; Email: pat@yourheartscore.com; Address: American Heart Association, 7272 Greenville Avenue, Dallas, TX 75231, United States. 
ods that optimize the skills of practitioners and patients. ${ }^{[2]}$ Research shows that the delivery of effective patient education has a significant impact on both the patient (e.g. better adherence to post-care instructions and quality of self-care at home) and the healthcare organization (e.g. lower readmittance rates). ${ }^{[3-6]}$ The Affordable Care Act, in particular, holds healthcare providers more accountable for patient education outcomes, including achievement of treatment goals, reduced readmissions, and lowered costs. ${ }^{[7]}$ As healthcare workers are faced with delivering patient education on a regular basis, they are often constrained by various issues that negatively impact the exchange. According to Koh et al. ${ }^{[8]}$ patient education is often delivered within a cycle of acute or crisis care that is informal, incidental, and highly fragmented. While there are effective models for patient education, they are often not feasible in more informal instructional situations, such as at a patient's bedside, or upon discharge.

Numerous factors impact the outcomes of patient education, in general, including the quality and mode of instruction. Also, informal patient instruction tends to be episodic and constrained by time pressures, with little attention to outcomes due to a lack of control over the learning process. ${ }^{[9]}$ These factors combined can have an adverse impact, resulting in problems such as improper use of medical equipment at home, general lack of understanding of one's condition, and minimal adherence to discharge instructions. ${ }^{[10-12]}$

The purpose of this article is two-fold. First, it explores current issues with informal patient education which prevent patients from reaching desired outcomes. Second, this article analyzes research findings that point to ways that nurses can support and enhance informal learning to make it more effective and productive. Using best practices for informal learning as a guide, ${ }^{[13]}$ ways to improve upon these types of educational exchanges are revealed and discussed.

\section{MethodS}

In this literature review, our goal is to identify: a) current issues with informal patient education practices and b) a clearer definition of how informal patient education occurs in practice. The search strategy focused on peer-reviewed research articles published after 2010. Other works, including books and conference proceedings were considered to provide a deeper understanding of the topics being examined.

The review was conducted using the Walden University Library. Specific database searches were conducted using CINAHL and Medline. We focused our search on literature relevant to patient education and informal learning, specifically seeking out works that merged these two areas. Specific

Published by Sciedu Press terms used in the search included: informal learning, patient education, adult education, adult learning, patient care, health literacy, discharge planning, discharge instructions, and care coordination.

\section{Definition}

As Lai, Khaddage, and Knezek ${ }^{[14]}$ note, the ways researchers have defined the term informal learning are varied, depending on the setting; it has been described as non-assessment driven, spontaneous, and self-directed. As we explore informal learning in the context of patient education, it is important to have a clear definition of how it manifests itself in this environment.

As Papen ${ }^{[1]}$ describes, patient education is typically selfdirected, self-managed, and focused on specific tasks in response to particular needs. Patient instruction also tends to be more time sensitive and episodic in nature as well. ${ }^{[9]}$ This type of learning can be described as informal; it is intentional, but not highly structured, and can include self-directed learning, coaching, and mentoring. ${ }^{[15]}$ Because of its unplanned nature, informal learning has the potential to take place anywhere at any time; therefore, it is not limited to the hospital or physician's office setting. Often, it takes place at the patient's home through web-based resources, such as online peer support groups; ${ }^{[16]}$ educational websites; $;{ }^{[17,18]}$ conversations with the care team and other patients; ${ }^{[19]}$ and other venues. These types of resources are important to learning, particularly during a health crisis when information is needed quickly. ${ }^{[20]}$

\section{Results}

Learning is impacted by numerous factors including how the information is delivered and the level of involvement of the patient. ${ }^{[7]}$ Informal learning opportunities certainly have a place in patient education; they are a convenient way to deliver critical information to patients in a timely, cost-effective manner. This informal approach also appeals to patients who need information quickly, or who prefer to seek out information on their own in a less-structured environment. Informal patient education is most likely going to remain an important part of the patient care cycle, so it is essential to find ways to enhance and improve current practices. To do this, we examine several areas that further describe current issues that impact the quality informal learning.

\subsection{Quality measures and assessment}

An important practice for any type of educational delivery is the use of quality measures and assessment. Research has shown that quality measures have a positive, direct link to cost-savings, such as reduction of Medicare reimburse- 
ment. ${ }^{[21]}$ In patient education, in general, quality measures have been established at the national level and are core indicators to assure compliance with evidence based practices. The key to effective quality measures and assessment is a multi-pronged approach that may include: assessing patient learning needs, identifying social determinants of health, understanding patient learning preferences, and considering health literacy, while also providing guidelines for discharge instructions and an education plan. ${ }^{[22]}$ Post-instruction check for understanding is also critical to ensure the information that was delivered to the patient was understood. As a followup measure, patients might be asked to rate how well they understood their medication instructions following discharge, instructions following discharge. Tools such as the Patient Education Materials Assessment Tool (PEMAT), for example, help nurses evaluate factors such as the understandability and actionability (i.e. how well does the patient understand what they need to do) of instructional guides. ${ }^{[23]}$

The nature of patient education makes this multi-faceted approach to quality measurement and assessment limiting even more so in informal scenarios. Research has shown that a lack of time and/or validated assessment tools that can be easily administered in a clinical setting result in very little in the way of actual assessment of patient learning. ${ }^{[24]}$ Assessment of informal education in a clinical setting often focuses on behavior change and outcomes, yielding fragmented information that does not provide a clear picture of whether or not learning objectives were achieved. ${ }^{[25,26]}$ Along these lines, healtcare workers, including nurses, often rely on more casual assessment, such as observing the types of questions the patient is asking, and the patient's ability to repeat, in their own words, what they have learned. ${ }^{[27]}$ Research shows, despite quality measures, gaps remain between patients' perceptions of instruction, and the actual information provided by the nurse due to factors such as readability issues. ${ }^{[28]}$ For example, patients with low literacy skills may have language barriers, in addition to low literacy skills (including math literacy), and lower baseline knowledge of health, ${ }^{[29]}$ making it difficult to assess learning, particularly in one casual discussion or survey.

\subsection{Absence of structured curriculum}

Nurses rely heavily on an informal exchange or resources in lieu of structured curriculum, creating a learning environment inconsiderate of any defined agenda. For example, a patient may be given a pamphlet directing them to a website or patient care portal for more information about their condition or for follow-up care instructions. While this informal approach is often due to time sensitivity, it may also be a result of a lack of formalized training in effective teach- ing practices of the healthcare workers, including nurses, who are responsible for educating patients. ${ }^{[13]}$ Conversely, more well-known approaches to patient education, such as Teach to Goal (TTG) ${ }^{[29]}$ and the American Heart Association guidelines for cardiopulmonary resuscitation, ${ }^{[30]}$ rely on more comprehensive curriculum and instructional expertise for them to be effective. Along these lines, for example, the Health Literacy Universal Precautions Toolkit provides a framework for providing patient education using a more patient- centric format, including eliminating the use of jargon, providing small bits, emphasizing what the patient needs to know and do. ${ }^{[27]}$ These frameworks are counterintuitive to how informal education manifests itself in healthcare, which often happens in the patient's home, during casual exchanges, and other venues.

Informal patient education is often incorporated in tandem with more formalized programs and generally relies on a checklist of topics, talking points, and techniques such as teach-back. ${ }^{[27]}$ This may include hand-written or pre-printed instructions, focused on plain language with clear and concise messaging. TTG, ${ }^{[29]}$ a curriculum designed for heart failure patients with low literacy skills, focuses on developing self-management skills resulting in reduced readmission and death. TTG, as opposed to single session interventions, such as discharge instructions at the time of discharge, starts out by teaching foundational knowledge and skills, and works towards building content over time. Cardiopulmonary resuscitation training for non-medical personnel has many similarities compared to TTG, including being objective and skill based, emphasizing simplicity with a structured approach this is practiced until mastery is achieved. ${ }^{[30]}$ Digital tools and technology are being used in patient education to track biometric data, such as physical activity, blood pressure and weight, provide education, and social support. ${ }^{[31]}$

\section{RECOMMENDATIONS}

Tannebaum, Beard, McNall, and Salas ${ }^{[13]}$ indicate four components critical to informal learning which include intent, experience or action, feedback, and reflection. For learning to occur, it is necessary for an individual to be "conscious of the need to learn". ${ }^{[3]}(\mathrm{p} 307)$ Also, an individual must learn by doing as part of the informal learning process. Marsick and Watkins ${ }^{[32]}$ describe this as incidental learning, a subcategory of informal learning, where individuals learn through trial-and-error, for example. Learning by doing allows for reflection on mistakes, ${ }^{[32]}$ and further improvement or refinement of processes. The authors present strategies for supporting and enhancing informal patient education, guided by four areas: desire to learn, learning by doing, feedback, and reflection. ${ }^{[13]}$ 


\subsection{Desire to learn}

Nurses can assess the learning needs of their patients based on cultural, social determinants (including health literacy) and the types of patients by diagnoses. The effectiveness of patient education in a healthcare setting is often determined by the motivation, self-directedness, and level of engagement of the patient. ${ }^{[34]}$ Educational methods, therefore, must also have a motivating and engaging component, and accommodate patients who prefer self-directed learning. To work towards this, informal instruction can be designed based on assessment of patient needs, which can then, in turn, be used to develop engagement strategies. With this approach, behaviors, achievement of treatment goals, clinical outcomes, and perception of care can be measures of success.

Motivational interviewing ${ }^{[35]}$ is one strategy to help build intent, or desire to learn, in patients. Motivational interviewing is not a new technique; healthcare professionals typically use it in tandem with informal and quick delivery techniques in patient education, such as reflective listening with the goal supporting readiness for change. ${ }^{[36]}$ This strategy, however, must meet the needs of all patients - not just the motivated and self-directed. A key component, therefore, of building intent with informal learning is to focus on the relevance of the information.

Another strategy used to build intent is to focus on cognitive behavioral change strategies, such as goal setting, selfmonitoring, and relapse prevention. ${ }^{[37]}$ Baker et al. ${ }^{[29]}$ used a cognitive approach to explain the behavior, background information necessary to understand the behavior, and promote an attitude change. This was achieved by defining a limited set of the most important learning goals, providing content in small bits of information, and linking the content to a skill or behavioral goal. ${ }^{[29]}$

\subsection{Learning by doing}

Health education and intervention programs provided in a group setting, such as cardiac and pulmonary rehabilitation, diabetes self-management, and weight loss provide a venue for informal education. Informal conversations with healthcare professionals and other patients in these forums give patients an opportunity to draw upon the experiences and model the behavior of others. ${ }^{[37]}$ A key to drawing on the experiences and actions of others with informal learning is by making the interactions as personalized as possible. To do this, adult learners draw upon their own experiences. ${ }^{[38]}$ Modeling behaviors and simulation of skills can provide a framework for the patient as they encounter their own personal experiences. ${ }^{[30]}$

Activity and skill based programs, such as cardiac rehabilita- tion, diabetes self-management, and lifestyle programs can be provided in a group and social setting to promote behavior change by allowing patients to learn by doing and model the behavior of other patients. ${ }^{[39]}$ Modeling is used to demonstrate specific skills and behaviors, such as food preparation, exercise, and monitoring of blood pressure and glucose. ${ }^{[37]}$ Modeling also can be used by health educators to simulate and standardize specific instructional methods. ${ }^{[40]}$

\subsection{Feedback and reflection}

Feedback is a critical part of learning; in more formal patient education scenarios, patients look to nurses for specific information related to their progress or learning. One study focused on assessment and feedback in the stroke rehabilitation process revealed barriers to feedback including confidentiality concerns, inconsistency in information, and lack of staff availability to engage in the feedback process. ${ }^{[33]}$ Lack of feedback in informal learning situations results in a false assumption that the learner (i.e. patient) has an accurate understanding. ${ }^{[3]}$ In informal learning, there is often minimal feedback (if any at all), placing the responsibility to the patient to reflect. Without reflection, there is less absorption or understanding of the information. ${ }^{[13]}$ To build a new framework for supporting and informal patient education, we explore the areas described above in more depth.

It is often challenging for nurses to elicit or receive viable patient feedback in informal education situations. Teachback can support quick-delivery, informal patient education scenarios by having the patient repeat back the information that is presented to them. ${ }^{[27]}$ Technology, such as wearable devices, can also provide feedback to the patient on areas such as level of physical activity, blood pressure, sleep, and glucose levels. In addition to providing feedback, web based care coordination systems promote two-way communication between the patient and their healthcare team. ${ }^{[31]}$ Informal methods are used to supplement formal educational sessions in the healthcare setting by providing small 'chunks' of information over multiple encounters. ${ }^{[29]}$ An example of this is a nurse or caregiver engaging the patient in a brief encounter about a specific topic, such as their medications. Conducting multiple brief, and informal sessions in the healthcare setting, and extending the other educators, care givers, and patients may be more effective by allowing the react to the feedback from the patient. ${ }^{[29]}$ A key component of using feedback in informal education is to make the information interactive.

Reflection is most often accomplished in the healthcare setting by allowing patient to share their experiences with other patients. This element is often overlooked, or avoided completely due to privacy concerns. Social and emotional support, however, is a key element of patient learning, especially 
in cancer, multiple sclerosis, and ALS. ${ }^{[41]}$ Peer-to-peer mentoring through face-to-face interaction and digital tools can enhance the information provided by the healthcare professional and are being used in hypertension, diabetes, and AIDS awareness. ${ }^{[42]}$ Patient centered programs such as $\mathrm{Pa}-$ tients Like Me are emerging as platforms for communication and education. ${ }^{[43]}$ These platforms are being used to provide patients with an active role in their own health, and allow patients to share their data, and insights, with other patients and researchers. Social support platforms provide an opportunity to informal learning. Rather than reading a brochure or watching a video, the patient can participate in active discussions with experts and other patients. Integrating social support into a healthcare environment, however, can be challenging for healthcare professionals, who must balance privacy issues, time commitment, and the need to filter out information that is not credible. A key component of using reflection in informal learning is to focus on the social support system of the patient.

\section{Conclusion}

Informal, quick delivery instruction is common way for nurses to educate patients, emerging because of its convenience as a way to deliver critical information to patients in a timely, cost-effective manner. It also appeals to patients who are more self-directed and like to explore information on their own time, at their own pace. There are ways, however, key deficiencies in informal approaches can be identified as ways to make the patient experience more effective. We have learned that while patient education is frequently informal, incidental, and quick, it does not need to be unstructured. Nurses and other healthcare professionals should design their educational methods to be aligned with the learning needs of the patients. This might include getting an earlier start to the educational experience to allow for more encounters. Also, patient educators should standardize, practice, and simulate their teaching methods, just like they do with other skills and actions.
Informal methods are well suited for nurses providing patient education in a healthcare setting. Nurses must balance operational and time pressures with the need to provide the patients with needed information. While the healthcare setting is not conducive to formal educational approaches, informal approaches can more easily be provided as the opportunity for instruction presents itself. Examples of informal methods conducted in the healthcare setting include discharge instruction from the acute setting; brief, serial conversations with the patient and family members while performing other patient care duties; conversations with the patient during programs, such as cardiac rehabilitation or physical therapy; and ongoing interactions with patients in both live and virtual formats.

With increasing pressure on nurses and other healthcare providers to be accountable for the long-term outcomes of patients there is an increasing need to provide effective patient education. Formal educational approaches are difficult to provide in the healthcare setting. Informal methods, however, can be performed by healthcare providers within their scope of work. A lack of quality and assessment measures and a lack of a structured curriculum present challenges to information methods. Best practices for informal methods are those that facilitate a desire to learn, provide hands-on instruction, and allow for feedback.

While informal patient education strategies are valuable in healthcare settings, it is important to recognize their limits. Nurses and other patient care workers should find ways to support informal patient learning to bridge gaps left by lack of curriculum, assessment, or quality improvement measures. By engaging patients in strategies related to motivation, activities, feedback, and other areas, nurses can begin to enhance instances of informal learning in the patient care cycle.

\section{CONFlicts of InTEREST Disclosure}

The authors declare that there is no conflict of interest statement.

\section{REFERENCES}

[1] Papen U. Informal, incidental and ad hoc: the information-seeking and learning strategies of health care patients. Language and Educ. 2012; 26: 105-119. http://dx.doi.org/10.1080/09500782. 2011.642878

[2] Nielsen-Bohlman L, Panzer AM, Kindig DA (Ed.). Health Literacy: A prescription to end confusion. Washington, DC: National Academies Press; 2004.

[3] David D. Heart failure discharge instructions: a comparative content analysis of notes written by nurse practitioner and physician providers. In 43rd Biennial Convention Proceedings (07 November11 November 2015). STTI.

[4] Dorresteijn JA, Kriegsman DM, Assendelft WJ, et al. Patient education for preventing diabetic foot ulceration. The Cochrane Library. 2014. http://dx.doi.org/10.1002/14651858.cd0014 88. pub5

[5] Dorresteijn JA, Valk GD. Patient education for preventing diabetic foot ulceration. Diabetes/Metabolism Research and Reviews. 2012; 28(S1): 101-106. PMid:22271733 http://dx.doi.org/10.1002 /dmrr. 2237 
[6] Wei MY, Ito MK, Cohen JD, et al. Predictors of statin adherence, switching, and discontinuation in the USAGE survey: understanding the use of statins in America and gaps in patient education. J of Clin Lipidology. 2013; 7(5): 472-483. PMid:24079289 http://dx.doi.org/10.1016/j.jacl.2013.03.001

[7] Hoving C, Visser A, Mullen P, et al. A history of patient education by health professionals in Europe and North America: from authority to shared decision making. Patient Educ and Counseling. 2010; 78: 275-281. PMid:20189746 http://dx.doi.org/10.1016/j . pec .2010 .01 .015

[8] Koh HK, Berwick DM, Clancy CM, et al. New federal policy initiatives to boost literacy can help the nation move beyond the cycle of costly crisis care. Health Affairs. 2012; 31: 434-443. PMid:22262723 http://dx.doi.org/10.1377/hlthaff .2011.1169

[9] Werquin P. The missing link to connect education and employment: recognition of non-formal and informal learning outcomes. J of Educ and Work. 2012; 25: 259-278. http://dx.doi.org/10.1080/1 3639080.2012 .687574

[10] Engel KG, Buckley BA, Forth VE, et al. Patient understanding of emergency department discharge instructions: where are knowledge deficits greatest?.Acad Emergency Medicine. 2012; 19(9): E1035-E1044. PMid:22978730 http://dx.doi.org/10.1111/j .1553-2712.2012.01425.x

[11] Hamdan AL, Ahmed A, Abdullah AL, et al. Improper inhaler technique is associated with poor asthma control and frequent emergency department visits. Allergy Asthma Clin. Immunol. 2013; 9: 8. PMid:23510684 http://dx.doi.org/10.1186/1710-149 2-9-8

[12] Mulsow JJ, Feeley TM, Tierney S. Beyond consent - improving understanding in surgical patients. The American J of Surgery. 2012; 203: 112-120. PMid:21641573 http://dx.doi.org/10.1016/j . amj jurg. 2010.12.010

[13] Tannenbaum SI, Beard RL, McNall LA, et al. Informal learning and development in organizations. Learning, Training, and Development in Organizations. 2010; 303-332.

[14] Lai KW, Khaddage F, Knezek G. Blending student technology experiences in formal and informal learning. J of Computer Assisted Learning. 2013; 29: 414-425. http://dx.doi.org/10.1111/j cal. 12030

[15] Marsick VJ, Watkins KE. Informal and incidental learning. New Directions for Adult and Continuing Education. 2001; 89: 25-34. http://dx.doi.org/10.1002/ace.5

[16] Naslund JA, Grande SW, Aschbrenner KA, et al. Naturally occurring peer support through social media: the experiences of individuals with severe mental illness using YouTube. PloS One. 2014. PMid:25333470 http://dx.doi.org/10.1371/journal . pone. 0110171

[17] Nicolaou M, Armstrong R, Hassell AB, et al. Musculoskeletal health professional use of internet resources for personal and patient education: results from an online national survey. The Open Rheumatology J. 2012; 6: 190. PMid:22970071

[18] Salonen A, Ryhänen AM, Leino-Kilpi H. Educational benefits of Internet and computer-based programmes for prostate cancer patients: a systematic review. Patient Educ and Counseling. 2014; 94: 1019. PMid:24021418 http://dx.doi.org/10.1016/j . pec. 201 3.08 .022

[19] Chugh A, Williams MV, Grigsby J, et al. Better transitions: improving comprehension of discharge instructions. Frontiers of Health Services Mgt. 2009; 25: 11-32. PMid:19382514

[20] Grover K. Online social networks and the self-directed learning experience during a health crisis. International Journal of Self-Directed Learning. 2015; 1.
[21] Kocher RP, Adashi EY. Hospital readmissions and the affordable care act: paying for coordinated quality care. $\mathrm{J}$ of the American Medical Assoc. 2011; 306: 1794-1795. PMid:22028355 http: //dx.doi.org/10.1001/jama.2011.1561

[22] Schmaltz SP, Williams SC, Chassin MR, et al. Hospital performance trends on national quality measures and the association with joint commission accreditation. J of Hospital Medicine. 2011; 6: 454-461. PMid:21990175 http://dx.doi.org/10.1002/jhm. 905

[23] The Patient Education Materials Assessment Tool (PEMAT) and User's Guide. Available from: http: //www.ahrq.gov/professionals/prevention-chronic -care/improve/self-mgmt/pemat/pemat1.html

[24] Alicea-Planas J, Pose A, Smith L. Barriers to providing health education during primary care visits at community health centers: Clinical staff insights. J of Community Health. 2015: 1-6.

[25] Berkman ND, Sheridan SL, Donohue KE, et al. Low health literacy interventions and outcomes: an updated systematic review. Annals of Internal Medicine. 2011; 155: 97-107. PMid:21768583 http: // dx.doi .org/10.7326/0003-4819-155-2-201107190-00005

[26] Taggart J, Williams A, Dennis S, et al. A systematic review of interventions in primary care to improve health literacy for chronic disease behavioral risk factors. BMC Family Practice. 2012; 13: 1-12. PMid:22656188 http://dx.doi.org/10.1186/1471-229 6-13-49

[27] DeWalt DA, Callahan LF, Hawk VH, et al. Health literacy universal precautions toolkit. 2010. Rockville, MD: Agency for Healthcare Research and Quality.

[28] Svider PF, Agarwal N, Choudhry OJ, et al. Readability assessment of online patient education materials from academic otolaryngology-head and neck surgery departments. American Journal of Otolaryngology. 2013 Feb 28; 34(1): 31-5. PMid:22959363 http://dx.doi.org/10.1016/j.amjoto.2012.08.001

[29] Baker DW, DeWalt DA, Schillinger D, et al. "Teach to goal": theory and design principles of an intervention to improve heart failure self-management skills of patients with low health literacy. J of Health Communication. 2011; 16: 73-88. PMid:21951244 http://dx.doi.org/10.1080/10810730.2011.604379

[30] Bhangi F, Mancini ME, Sinz E, et al. Part 16: Education, implementation, and teams: 2010 American Heart Association guidelines for cardiopulmonary resuscitation and emergency cardiovascular care. Circulation. 2010; 122: s920-s933. PMid:20956232 http: //dx.doi.org/10.1161/CIRCULATIONAHA.110.971135

[31] Beatty AL, Fukoaka Y, Whooley MA. Using mobile technology for cardiac rehabilitation: A review and framework for development and evaluation. Journal of the American Heart Association. 2013; 2: e000568. PMid:24185949 http://dx.doi.org/10.1161/JAHA . 113.000568

[32] Marsick, VJ, Watkins KE. Informal and incidental learning in the workplace. New York, NY: Routledge; 2015.

[33] Tyson S, Burton LJ, McGovern A, et al. Services users' views of the assessment process in stroke rehabilitation. Clinical Rehabilitation. 2014; 28: 824-831. PMid:24572140 http://dx.doi.org/10.11 $77 / 0269215514523300$

[34] Coleman EA, Parry C, Chalmers S, et al. The care transitions intervention: Results of a randomized controlled trial. Arch Intern Med. 2006; I66: 1822-1828. PMid:17000937 http://dx.doi.org/10. 1001/archinte.166.17.1822

[35] Miller, WR, Rollnick, S. Motivational interviewing: preparing people for change. 2002. New York. The Guilford Press.

[36] Prochaska JO, DiClemente CC. Stages and processes of self-change of smoking: toward an integrative model of change. J of Counseling 
and Clinical Psychology. 1983; 51: 390-395. http://dx.doi.org /10.1037/0022-006X.51.3.390

[37] Artinian NT, Fletcher GF, Mozaffarian D, et al. Interventions to promote physical activity and dietary lifestyle change for cardiovascular risk factor reduction in adults: a scientific statement from the American Heart Association. Circulation. 2010; 122: 406 441. PMid:20625115 http://dx.doi.org/10.1161/CIR.0b013 e3181e8edf 1

[38] Fisher MJ, King J. The self-directed learning readiness scale for nursing education revisited: A confirmatory factor analysis. Nurse Education Today. 2010; 30(1): 44-48. PMid:19541394 http: //dx .doi.org/10.1016/j.nedt.2009.05.020

[39] Courtney M, Conard SE, Dunn P, et al. The Game of Health: an innovative lifestyle change program implemented in a family practice. J of the American Acad of Nurse Practitioners. 2011; 23: 289-
297. PMid:21649771 http://dx.doi.org/10.1111/j.1745-7 599.2011.00604.x

[40] Kelly MA, Hager P. Informal learning: relevance and application to healthcare simulation. Clin Simul in Nursing. 2015; 11: 376-382. http://dx.doi.org/10.1016/j.ecns.2015.05.006

[41] Richards T, Coulter A, Wicks P. Time to deliver patient centered care. British Medical J. 2015; 350: h530. PMid:25670197 http: //dx.doi.org/10.1136/bmj.h530

[42] Funnell M. Peer-based behavioural strategies to improve chronic disease self-management and clinical outcomes: evidence, logistics, evaluation considerations and needs for future research. Family Practice. 2010; 27: i17-i22. PMid:19509083 http://dx.doi.org/10. 1093/fampra/cmp027

[43] Wicks P, Massagli M, Frost J, et al. Sharing health data for better outcomes on Patients Like Me. J of Medical Internet Research. 2010; 12 : e19. PMid:20542858 http://dx.doi.org/10.2196/jmir.1549 